\title{
SCARCITY APPEAL IN ADVERTISING - EXPLORING THE MODERATING ROLES OF NEED FOR UNIQUENESS AND MESSAGE FRAMING
}

\begin{abstract}
In this paper we examine the differences in the impact of message framing and scarcity appeal types in advertisements on the consumers with varying levels of need for uniqueness (NFU). Results from two experimental studies support a two-way NFU x scarcity interaction, wherein participants with lower levels of NFU show a greater impact of demand (vs. supply) scarcity appeal on their attitudes and purchase intentions; whereas the participants with higher levels of NFU show a greater impact of supply (vs. demand) appeal. In addition, we found support for a three-way interaction, which shows that both under gain and loss frames, participants with lower levels of NFU prefer demand over supply appeal whereas under the loss frame, participants with higher levels of NFU prefer supply over demand appeal. We discuss the conceptual contribution and managerial implications of these findings.
\end{abstract}

Keywords: Advertising, Need for Uniqueness, Message Framing, Scarcity appeal 
Marketers have long used the concept of scarcity appeal to drive demand for products (Lynn 1991) based on the commodity theory which posits that "any commodity will be valued to the extent it is unavailable" (Brock 1968, p.246). Hence, it is not surprising to see phrases, such as 'nearly sold out due to high demand' or 'already $80 \%$ of our stock sold', and 'limited edition' in everyday marketing communications (Gierl and Huettl 2010). A number of psychological processes may drive the value enhancing nature of scarcity appeals, including reactance theory (Brehm 1966), scarcity as a heuristic cue signalling quality and premium (Lynn 1991) and a desire to gain social status from consumption (Gierrl and Huettl 2010). Research on the scarcity appeal also shows that as the perceived scarcity of a good increases so does its perceived value and desirability (Lynn 1991; 1992).

Current literature distinguishes between scarcity appeals that are driven by 'excess demand' or based on 'limited supply' and argues that these supply and demand generated scarcity appeals may send very different signals to the market place (Gierrl and Huettl 2010; Eisend 2008). For example, demand based appeal can signal popularity and band wagon consumption, while supply appeals may stand for counter conformity and snob-effect (Irmak, Vallen, and Sen 2010; Van Herpen, Pieters, and Zeelenberg 2005). To explore this further, researchers have studied (see Lynn 1991 for a review) the interaction between scarcity appeals and need for uniqueness (NFU), an individual trait that represents the need to establish a separate identity by pursuing self-distinguishing behaviour (Fromkin and Snyder 1980).

Early research showed that individuals may try to fulfil their need for uniqueness by acquiring scarce possessions, although the robustness of these findings has been questioned (Lynn 1991; Snyder 1992). However, despite recent research into this important issue, there are still many research gaps and inconclusive findings. For example, Van Herpen et al. (2005) show that NFU also moderates the relation between scarcity and perceived quality but only when scarcity is due to supply limitations and not when it is due to excess demand, 
because excess demand implies that the product is popular rather than exclusive. However, these researchers focus on quality inferences and do not explore the impact of the interaction between scarcity and NFU on consumer attitudes or behavioral intentions. (Gap 1)

Prior research also found that when consumers are categorized into high and lowNFU groups based on a median split, they exhibit different attitudes toward 'framing effect', with the high (vs. low) NFU consumers preferring a risky (vs. sure) choice option under a loss (vs. gain) frame (Simonson and Nowlis 2000; Tversky and Kahneman 1981). This combined with limited theoretical evidence that framing might moderate the effect of NFU on judgment (Ames and Iyengar 2005), calls for an empirical investigation into the three way interaction between scarcity appeal, NFU and gain vs. loss framing, which will help scholars understand how perceptions of uniqueness are influenced by the interaction between message framing and scarcity appeal types (Eisend 2008; Ames and Iyengar 2005). (Gap 2)

We address both these gaps in this paper. First, we hypothesize and investigate the interaction between scarcity appeal type and NFU in the context of advertising effectiveness by exploring its impact on four different types of outcome variables, namely attitude towards the advertisement, attitude towards the brand, purchase intention and perceived value (Eisend 2008; Simonson and Nowlis 2000). Second, we study how consumers with different levels of need for uniqueness respond to scarcity appeal types (demand versus supply), especially when it is presented under loss versus gain frames. In other words, we explore the three-way interaction between scarcity appeal type, message framing and NFU, which is the key contribution of this study.

\section{THEORETICAL FRAMEWORK AND HYPOTHESIS}

\section{Scarcity Appeal and Need for Uniqueness}


Scarcity based on excessive demand leads consumers to infer that the product might be popular because they see others purchasing the product (Gierrl and Huettl 2010; Van Herpen, Pieters, and Zeelenberg 2009; 2005). Further, product scarcity due to excessive consumer demand is a market-driven phenomenon and outside the marketers' control because they are unable to predict such demand beforehand (Aguirre-Rodriguez 2013). However, marketers' often engage such subjective signals (e.g., nearly sold out) as a part of 'advertising puffery', which is a tactic used to indicate a product's popularity to the consumers (Aguirre-Rodriguez 2013). As a result when consumers are unsure of the product value, they may rely on such indirect information based on popularity, and adopt popular consumption behaviour similar to the bandwagon effect (Van Herpen, Pieters, and Zeelenberg 2009).

Supply driven scarcity effect on the other hand has different connotations. First, as compared to the demand scarcity appeal, supply scarcity appeal may be perceived as more objective because marketers control their product distribution decisions (Aguirre-Rodriguez 2013). Second, consumers may value the exclusivity of possessing such rare products which can emphasize their uniqueness (Gierrl and Huettl 2010; Lynn 1991). For example, Gierrl and Huettl (2010) argue that purchasing limited edition products can help consumers to signal good taste, and be admired by friends. Possession of such exclusive products also provides increased value for those people who desire snob-effect (Irmak, Vallen, and Sen 2010).

Based on the above, it seems that supply-scarcity appeals may be more effective than demand appeals with consumers who have a uniqueness motive. In the marketing literature, certain consumers are described as being pre-disposed to expressing their uniqueness through consumption of differentiated products, a phenomenon referred as 'need for uniqueness' (Snyder and Fromkin 1980). People with higher need for uniqueness (NFU) prefer products that help them differentiate from others (Tian, Bearden, and Hunter 2001). Tian et al. (2001) had originally developed a 31-item scale to measure consumer's need for uniqueness. Ruvio, 
Shoham, and Brencic (2008) further developed a shorter version of the NFU scale with good psychometric properties and external validity, which has been used for the current study.

Consumers' choice for scarce products may be moderated by their NFU as reflected by a 'NFU x Scarcity' interaction. Specifically, high-NFU individuals are attracted to scarce products as scarcity enhances product value (Snyder 1992; Lynn 1991). However this interaction effect was not found to be robust (Lynn 1991). More recently (Van Herpen, Pieters, and Zeelenberg 2005) show that consumers with higher need for uniqueness preferred scarce products due to limited supply, albeit not in the demand scarcity condition.

In this paper, we look at the differential impact of demand versus supply scarcity appeal on consumers who are driven by high versus low need for uniqueness motivation. Firstly, evidence shows that individuals with higher levels of NFU do not yield to majority influence, such as agreeing with popular social opinion (Imhoff and Erb 2009). Evidence exists in the domain of consumption in support of high-NFU subject's resistance to majority influence. For example, high-NFU people are less likely to be persuaded by advertising puffery and compromise options in choice (Simonson and Nowlis 2000). In general it was found that high-NFU individuals preferred unconventional choice options which were guided by non-obvious as compared to straightforward reasons (Simonson and Nowlis 2000).

Low-NFU people also yielded more to majority influences (Imhoff and Erb 2009), as evident in the domain of consumption. For example, low-NFU participants are more persuaded by advertising puffery and compromise option in choices (Simonson and Nowlis 2000). Based on the above, low-NFU people are likely to prefer the demand over supply appeal, as it signifies majority influence (e.g., bandwagon consumption). In contrast, their high-NFU counterparts would prefer supply over demand appeal, as it supports their predisposition to avoid majority influence, thereby supporting their natural tendency to achieve 
distinctiveness through consumption. Further, in line with research on how scarcity effect may enhance 'perceived value' in general and for mass media advertising (Eisend 2008; Lynn 1991), the effect of NFU on scarcity appeal is also expected to hold for this dependent variable in addition to the advertising effectiveness variables. Therefore,

H1: The impact of scarcity appeal on attitude toward the ad and toward the brand, purchase intention and perceived value will be moderated by NFU, such that (a) high-NFU participants will have higher attitude toward the ad and toward the brand, purchase intention and perceived value in response to supply (vs. demand) scarcity appeal, and (b) Low-NFU participants will have higher attitude toward the ad and toward the brand, purchase intention and perceived value in response to demand (vs. supply) scarcity appeal.

\section{Three-Way Interaction between Scarcity Appeal, NFU and Framing}

Message framing involves manipulating the way that a message's information is presented in order to optimize its impact on message receivers' reactions and behaviour (Rothman and Salovey 1997). 'Framing' messages can either convey the positive consequences of adopting a behaviour (a gain frame), or the negative consequences of not adopting a behaviour (a loss frame). Gamliel and Herstein (2011) further defined gain framing to assert benefits and loss framing to assert risks. Levin and Gaeth (1988) demonstrated that consumer's evaluation of the same product (ground beef) was higher when it was described in a gain (75\% lean) versus a loss frame (25\% fat).

A framing effect occurs when decision makers are more likely to select the sure outcome when evaluating the gain frame than when evaluating the loss frame, as shown through the classic Asian disease study of Tversky and Kahneman (1981). In this seminal study, the participants were given two choice options which were objectively the same, but 
described either in terms of gain or losses. When the options were presented in terms of sure gains (lives saved), the participants preferred the secure program. When the programs were presented in terms of losses (expected deaths), the participants chose the riskier option.

Simonson and Nowlis (2000) tested the impact of need for uniqueness on susceptibility to the framing effect. In their study, low (high) NFU participants were exposed to an 'Economic problem' modelled after the seminal Asian disease problem of Tversky and Kahneman (1981). Findings from this specific study showed that high-NFU participants were less likely to consider the sure option in the gain frame, or in other words exhibited a diminished susceptibility to the framing effect. However, their counterparts (i.e., low-NFU participants) showed the classic framing effect, and were more likely to choose the sure option in the gain frame.

Simonson and Nowlis (2000) further showed that high-NFU people are more likely to prefer a risky option while making an unconventional choice. In particular, during a choice between a sure gain and a gamble, high-NFU respondents were systematically more likely to select a gamble that involved the possibility of a loss, and less likely to choose a gamble that involved only gains (Simonson and Nowlis 2000). The high-NFU participants' diminished susceptibility to loss aversion was captured across two studies called loss aversion-study 1 and 2. In fact, in their loss aversion study 1, high-NFU participants' loss aversion tendency was even slightly reversed, and the participants demonstrated gain aversion. The authors subsequently ascribe this surprising result to the small size of the 'sure gain' in the gambling choice options. The low-NFU participants on the other hand showed greater loss aversion tendencies compared to their counterparts.

As discussed above, high (NFU) participants show diminished susceptibility to framing effect and loss aversion. Further, evidence shows that high-NFU people are more 
likely to demonstrate socially risky displays of dissension behaviour as evidenced through product choice with high uniqueness ratings (Ames and Iyengar 2005; Tian and McKenzie 2001). A loss frame for a communication message can encourage risk seeking and justify non- conventional choices (Simonson and Nowlis 2000; Puto 1987). Extant research shows that risk-seeking tendency can enhance the attractiveness of supply appeal $(\mathrm{Ku}, \mathrm{Kuo}$, and Kuo 2012). For example, promotion-focused participants (high risk-seeker) preferred a supply appeal compared to prevention-focused counterparts (risk-avoider), the latter on the other hand were more attracted to the demand appeal (Ku, Kuo, and Kuo 2012).

The supply appeal ( as compared to the demand appeal) combined with the loss frame, therefore seems to be more persuasive for the high-NFU people because it provides strong reasons for a consumption decision that is unconventional and will further help these people to stand out (Simonson and Nowlis 2000). It also appeals to their risk seeking nature while making product decisions (Ames and Iyengar 2005; Tian and McKenzie 2001). Therefore, based on these evidence high-NFU participants will be more favorable towards the supply appeal, especially when it is presented under the loss frame. In contrast, a gain frame encourages loss aversion, which runs counter to the natural disposition of high-NFU people and hence will not appeal to them. In other words, for high-NFU people, a gain frame will not enhance the attractiveness of either demand or supply appeal (Simonson and Nowlis 2000).

A gain frame highlights the benefits of acquiring the scarce product and supports loss aversion. This frame should enhance the appeal of the demand scarcity (as compared to supply appeal) for the low-NFU participants, as these people are more likely to yield to majority influence and demonstrate loss aversion tendencies in their behavior ( $\mathrm{Ku}$ et al., 2012). In addition, gain frame should make it easier to justify the demand appeal which is considered a safer option in choice decisions, driven by popular consumption trends or the bandwagon effect. In comparison, a loss frame that encourages risky preferences would be 
incongruent with the tendency of low-NFU people who are more susceptible to normative influences. Therefore, low-NFU people are not expected to make a distinction between demand and supply scarcity appeals under a loss frame. Hence, the two-way NFU x scarcity interaction proposed in $\mathrm{H} 1$ will be further moderated by message framing as below:

H2: (a) High-NFU participants will have higher attitude toward the ad and toward the brand, purchase intention and perceived value in response to supply (vs. demand) scarcity appeal only under loss framing and no such differences under gain framing, and (b) Low-NFU participants will have higher attitude toward the ad and toward the brand, purchase intention and perceived value in response to demand (vs. supply) scarcity appeal, only under gain framing and no such differences under loss framing.

\section{STUDY 1}

\section{Method}

Design and Sample. We used a 2 (scarcity appeal: demand versus supply) X 2 (framing: gain versus loss) X 2 (need for uniqueness: low versus high) between-subjects experimental design for this study. The first two variables (scarcity appeal and framing) were manipulated using scenarios and NFU was measured. Two hundred and fifty one undergraduate students (125 females, mean age 23.48 years) from a large Australian university participated in the experiment in exchange for course credit. All the participants were randomly assigned to one of the four between-subjects conditions.

Procedure. As a cover story, the participants were told that they were completing two unrelated studies. First, the participants were asked to imagine that they were planning to buy fashion clothing. Message framing was manipulated by framing statements in terms of 
benefits gained or lost. In the gain frame, the participants wanted to buy fashion clothing from the retailer in order to stand out amongst friends; whereas in the loss frame, the participants did not want to lose out on the opportunity of standing out amongst their friends.

Next, the participants saw an advertisement from a fictitious retailer 'Couturier' that has entered the Australian market. Two different kinds of adverts highlighting demand versus supply scarcity appeals were created. Both adverts used the same pictures of a Caucasian couple and a fictional brand name 'Couturier', along with different copies to manipulate scarcity conditions. The wording used to manipulate demand generated scarcity stated 'Majority of stock sold' and 'Last pieces available now'. Supply generated scarcity was manipulated with the message 'Extremely limited stock' and 'Selected stores only'. All other elements (e.g., color, font and pictures) were held constant across both conditions.

After reviewing the advertisements, the participants answered the key dependent variables along with manipulation check questions. Two items were used as manipulation check for the scarcity conditions. Supply generated scarcity manipulation was checked by the item "There seems to be limited supplies of this product" while demand generated scarcity manipulation was checked by the second item "This product seems to be highly demanded", both with endpoints of $1=$ strongly disagree and $9=$ strongly agree.

Measures. Attitude toward the advertisement and the brand was measured using three nine-point scale items, namely the extent to which the participants considered the advertisement and the brand to be unpleasant/ unfavorable/not interesting (Cronbach's $\alpha=$ 0.94 and 0.95 respectively). Purchase intention was measured using three nine-point scale items - "I am likely to try out clothing from Couturier", "I am willing to buy clothing from Couturier" and "I will probably buy clothing from Couturier" - anchored at $1=$ strongly disagree and $9=$ strongly agree $(\alpha=0.96)$. After this the participants proceeded to answer 
some filler questions, following which they completed the NFU scale by Ruvio, Shoham and Brencic (2008), involvement items and other demographic variables. Involvement was measured with two nine-point items; "I am always staying up to date with new fashion" and "I am very much interested in fashion and clothes" $(1=$ strongly disagree, $9=$ strongly agree). Studies in marketing (Eisend 2008; Vakratsas and Ambler 1999) have shown that consumers' involvement with product category can influence their attitude toward the brand and the advertisement. Reliability for both the NFU and involvement scales were satisfactory $(\alpha=0.96$ and 0.83 respectively).

\section{Results}

Manipulation Check. The two manipulation check items were tested across all the independent variable conditions using MANOVA. Results showed that only scarcity type had a significant effect. The participants who saw the demand scarcity advert perceived the product to be highly demanded $\left(M_{\text {demand }}=6.90 ; M_{\text {supply }}=4.60 ; F(1,250)=107.32, p<\right.$ 0.001) in response to the demand manipulation check item. Similarly, the participants in the supply condition perceived the product to be in limited supply $\left(M_{\text {demand }}=4.89 ; M_{\text {supply }}=6.93\right.$; $F(1,250)=73.76, p<0.001)$, in response to the supply manipulation check item. No other results were significant. Hence, scarcity manipulation is successful.

Control Measures. Results of MANOVA with involvement as the dependent variable and scarcity, framing and NFU as the independent variables showed that consumers' involvement is not significantly related to any of the independent variables in the study. Hence, involvement was dropped from further analyses.

Moderated Multiple Regression Analysis. Next, we tested both our hypotheses using moderated multiple regression analysis as our model includes two dichotomous variables 
(scarcity and framing), one continuous variable (NFU) and their interactions with each other (Baron and Kenny 1986), as shown in the following regression model in equation (1):

$$
Y=a+b^{*} X+c^{*} A+d^{*} B+e^{*} X A+f^{*} A B+g^{*} X B+h^{*} X A B
$$

Where, $Y=$ Dependent variable (i.e., Attitude or Purchase Intention); X= NFU (Real number, 1 to 9$), A=$ Scarcity $(0=$ Supply, $1=$ Demand $) ; B=$ Framing $(0=$ Loss, $1=$ Gain $)$ and $\mathrm{a}, \mathrm{b}, \mathrm{c}, \mathrm{d}, \mathrm{e}, \mathrm{f}, \mathrm{g}$ and $\mathrm{h}$ are the regression parameters to be estimated.

According to Spiller et al. (2013), in order to test our hypothesis on the three way interaction, we first need to obtain a significant three way interaction "XAB". This has to be followed up with tests of simple AB interaction at meaningful levels of $X$. Since $X$ is an individual difference variable and uses an interval scale, Spiller et al. (2013) recommends that floodlight tests will be more appropriate at chosen values of the scale. Hence, we recoded $\mathrm{X}_{1}=\mathrm{X}-1, \mathrm{X}_{2}=\mathrm{X}-2, \ldots \mathrm{X}_{\mathrm{n}}=\mathrm{X}-\mathrm{n}$ etc. for each of the nine points in the NFU scale and substituted these values in the regression equation 1 to revise it as follows:

$$
Y=a_{n}+b_{n} * X_{n}+c_{n} * A+d_{n} * B+e_{n}^{*} X_{n} A+f_{n} * A B+g_{n} * X_{n} B+h_{n} * X_{n} A B
$$

The new coefficient $f_{n}$ for $A B$ interaction represents the simple interaction between scarcity and framing at different chosen values of NFU and it helps us test this interaction for a range of NFU values rather than compare the cell means for this interaction at different levels of NFU. A similar method has been used by others (e.g., Lamberton, Kristofferson, and Dahl 2013) to test hypotheses involving two and three-way interactions.

We tested H1 using floodlight analysis to discover the range of NFU values for which there is a significant difference in the impact of scarcity (demand vs. supply) appeals on the three DVs (attitude towards ad, attitude towards brand and purchase intention). Specifically, as advised by Spiller et al. (2013) for interactions between a continuous and a dichotomous 
variable, we first tested the significance of XA interaction and then inspected coefficient $c_{n}$, which represents the simple effect of scarcity appeal A $(0=$ Supply, $1=$ Demand $)$ at different values of NFU in equation 2. As shown in Table 1, there is a significant difference in the impact of scarcity type on attitude towards ad for the values of NFU below 6 and above 7; on attitude towards brand below and above 6 , and on purchase intention below 5 and above 6 .

The direction of the signs for the regression coefficients provides further insights. Specifically, a positive regression coefficient for attitude towards ad at NFU $=1(b=3.64, t=$ 5.22, $\mathrm{p}<0.001)$ in comparison to a negative coefficient at NFU $=9(\mathrm{~b}=-1.85, \mathrm{t}=-3.29, \mathrm{p}<$ 0.001) means that low (high) NFU participants preferred the demand (supply) over the supply (demand) appeal. We see a similar pattern of results for the regression coefficients for attitude towards brand and purchase intention. All these findings support H1.

\section{PLACE TABLE 1 ABOUT HERE}

Next, we tested $\mathrm{H} 2$ using the procedure employed by Lamberton, Kristofferson, and Dahl (2013) to conduct a series of floodlight analyses to test the scarcity*NFU interaction at different levels of NFU $\left(\mathrm{X}_{1}, \mathrm{X}_{2}\right.$ etc.) separately for the gain and loss frame. The upper panel of Table 2 shows the findings under loss frame and lower panel under gain frame.

For H2a we compared the upper and lower panels of Table 2 for high-NFU people only. First, as shown in the upper panel, the scarcity*NFU interaction is significant under the loss frame for attitude toward the ad for value of NFU above 7, and for attitude toward the brand and purchase intention (NFU above 6). Moreover, the negative coefficient at NFU $=9$ $(b=-1.85, t=-3.37, p<0.001)$ indicates that high-NFU people prefer the supply over the demand appeal under the loss frame. We notice a similar pattern of results for attitude toward the brand and purchase intention under the loss frame. Next, as shown in the lower panel of Table 2, i.e. under gain framing, the scarcity*NFU interaction is non-significant for high- 
NFU subjects for all the three outcome variables (i.e., attitude toward the ad, brand and purchase intention) as hypothesized. H2a is therefore supported.

\section{PLACE TABLE 2 ABOUT HERE}

Finally, we tested $\mathrm{H} 2 \mathrm{~b}$ by comparing the lower and upper panels of Table 2, but only for low-NFU subjects. Table 2 (lower panel) shows that under gain frame, the scarcity*NFU interaction is significant for attitude toward the ad and toward the brand (NFU below 7), and for purchase intention (NFU between 4 and 6 only). Further, positive regression coefficient for attitude toward the ad at $\mathrm{NFU}=1(\mathrm{~b}=1.9, \mathrm{t}=2.48, \mathrm{p}<0.01)$ shows that participants with low-NFU prefer the demand over supply appeal under the gain frame. However, this pattern of results only holds for attitude toward the ad and toward the brand (NFU between 1 and 6), but not for purchase intention. Hence, low-NFU participants seem to prefer the demand (vs. supply) appeal under gain frame but only for these two dependent variables.

Next, the upper panel of Table 2 shows a significant scarcity*NFU interaction for all the three dependent variables (attitude toward the ad, brand and purchase intention) at NFU values below 6. Moreover, a positive regression coefficient for attitude toward the ad for $\mathrm{NFU}=1(\mathrm{~b}=3.65, \mathrm{t}=5.42, \mathrm{p}<0.001)$ shows that similar to the gain frame, low-NFU participants also prefer the demand over supply appeal under the loss frame. This preference of low-NFU participants for demand over supply appeal under the loss frame is also noticed for the other two dependent variables (attitude toward the brand and purchase intention). Based on these findings, the two-way interaction between scarcity and NFU shows the same pattern for low-NFU subjects under both gain and loss frames, which does not support the existence of this effect only under gain frame as suggested in $\mathrm{H} 2 \mathrm{~b}$. Hence $\mathrm{H} 2 \mathrm{~b}$ is rejected.

\section{Discussion}


Findings from study 1 show full support for $\mathrm{H} 1$ and partial support for $\mathrm{H} 2$. We used floodlight tests to assess our hypotheses. First, the results of floodlight analyses show that the two way interaction (NFU x scarcity) is driven by low (high) NFU participants' preference for demand (supply) over the supply (demand) appeal for all the three dependent variables. The three way interaction is also supported by results of floodlight analyses, which show that high-NFU people prefer the supply appeal under loss frame. Their counterparts however preferred the demand over supply appeal under the gain frame as predicted for attitude towards ad and brand, but only for medium levels of NFU for purchase intention. Results from study 1 also show that under the loss frame low-NFU participants preferred the demand over supply appeal, which only confirms extant findings that these people's susceptibility to majority influence (e.g., bandwagon consumption) is sustained as the loss frame may provide a stronger justification for their decision (Imhoff and Erb 2009; Simonson and Nowlis 2000 ).

We conducted a second study to address limitations and extend the findings of our first study. First, we used a different type of product (a smart phone) to enhance generalizability of our results. Second, in line with existing literature, we used scenarios to manipulate supply versus demand appeal (Van Herpen, Pieters, and Zeelenberg 2009). Third, a stronger gain versus loss manipulation was used based on the findings from the first study that the scarcity * framing interaction held only for a limited range of NFU values for purchase intention. Finally, in line with the literature (Eisend 2008; Lynn 1991), this study used another key dependent variable, perceived value.

\section{STUDY 2}

\section{Method}

Design and Sample. We used the same 2 (scarcity appeal: demand versus supply) X 2 (framing: gain versus loss) X 2 (need for uniqueness: low versus high) between-subjects 
experimental design as in the first study and randomly allocated the participants to each condition. One hundred and twenty two undergraduate students (59 females, mean age 21.5 years) from a large Australian university participated in exchange for course credit. Once again, scarcity appeal and framing were manipulated and need for uniqueness was measured.

Procedure. As in the first study, the participants were told the cover story that they were participating in two unrelated studies. Scarcity appeal was manipulated through a scenario. In the first part, the participants imagined that they were in the market for a smart phone and came across an advertisement for a fictitious brand of phone called 'Vertos' from a leading manufacturer. They were further asked to imagine that they visited the nearest retailer to learn that the phones were limited editions and were released in extremely small quantities to selected retailers only (supply scarcity) or they were extremely popular and sold out ( demand scarcity). Framing was manipulated in a similar fashion to study 1, but with slight differences. In the gain frame, the participants were told that if they purchased the phone it would give them an opportunity to stand out and 'look cool', whereas in the loss frame, the participants learned that if they did not purchase the phone, they would lose an opportunity to stand out and 'look cool'.

Measures. After reading the scenarios, the participants answered the key dependent variables along with manipulation checks. Attitude toward the brand was measured with three nine-point scale items - the extent to which the participants considered the brand to be unpleasant/ unfavorable/not interesting $(\alpha=0.92)$. Purchase intention was measured with three nine point Likert scale items - "I will try out the new Vertos", "I am willing to buy the new Vertos", and "I will probably buy the new Vertos" $(1=$ strongly disagree, $9=$ strongly agree) as anchors, showing good reliability $(\alpha=0.95)$. 
We also measured an additional dependent variable 'perceived value', adapted from Eisend (2008) and measured with three nine point scale items; the extent to which the participants considered the value of the offer to be less attractive/undesirable/non valuable ( $\alpha$ $=0.92)$. After this the participants answered the manipulation check questions, followed by some filler questions. For scarcity manipulation check, the participants answered a question regarding whether they believed the product to be in: 'limited supply' versus 'high demand'. Similarly, for framing manipulation, the participants answered a single question on whether by having/not having the product they would gain or lose an opportunity to stand out.

Next, the participants completed the same NFU scale as in study $1(\alpha=0.92)$, followed by involvement, knowledge and familiarity and other demographic variables which past studies have shown to influence ad and brand attitudes (Eisend 2008; Vakratsas and Ambler 1999). Involvement was measured by three items $(\alpha=0.80)$, "I am interested in smart phones". "Smart phone is important to my lifestyle", and "Smart phone is relevant to my lifestyle"; while knowledge used items such as, "I am knowledgeable about smart phones", "I can talk about smart phones for a long time" $(\alpha=0.70)$. Finally, familiarity was measured with a single item - "I am very familiar with smart phones".

\section{Results}

Manipulation Check. MANOVA results with manipulation check items as the dependent variable along with scarcity, framing and NFU as the independent variables showed only main effect for scarcity and framing. In particular participants believed the phone to be in high demand (limited supplies) in response to the demand versus supply scenario $\left(M_{\text {demand }}=7.24 ; M_{\text {supply }}=3.63 ; F(1,120)=70.88, p<0.001\right)$. Similarly, participants believed that having/not having the product led to gaining/losing an opportunity to stand out 
$\left(M_{\text {gain }}=7.03 ; M_{\mathrm{loss}}=4.14 ; F(1,120)=67.06, p<0.001\right)$. Hence, both scarcity appeal and message framing manipulations are successful.

Control Measures. MANOVA with involvement, knowledge and familiarity as dependent variables and NFU, scarcity and framing as the independent variables shows that the control variables were not related significantly to the independent variables in the study. Hence these were eliminated from further statistical analyses.

Moderated Multiple Regression Analysis. Similar to the first study, we tested both our hypotheses using moderated multiple regression analysis with the three independent variables (scarcity, NFU and framing) and their interactions with each other (Baron and Kenny 1986) to predict three dependent variables (attitude towards the brand, purchase intention and perceived value), followed by similar floodlight analysis techniques described under equations 1 and 2 for study 1 . Similar to first study we coded $Y=$ Dependent variable (i.e., attitude towards the brand, purchase intention or perceived value); $X=$ NFU (Real number, 1 to 9$), \mathrm{A}=$ Scarcity $(0=$ Supply, $1=$ Demand $) ; \mathrm{B}=$ Framing $(0=$ Loss, $1=$ Gain $)$ and $\mathrm{a}, \mathrm{b}, \mathrm{c}$, $\mathrm{d}, \mathrm{e}, \mathrm{f}, \mathrm{g}$ and $\mathrm{h}$ are the regression parameters to be estimated.

To test H1, we again followed Spiller et al. (2013) to look at the coefficients of $c_{n}$ in regression equation 2, to explore the range of NFU values for which there is a significant difference in the impact of scarcity (demand vs. supply) appeals on the three DVs (attitude toward the brand, purchase intention and perceived value). As shown in Table 3, there is a significant difference in the impact of scarcity type on attitude towards brand for the values of NFU below 4 and above 5; on purchase intention below 3 and above 5, and on perceived value below 4 and above 7 . A positive regression coefficient for attitude towards brand for $\mathrm{NFU}=1(\mathrm{~b}=1.88, \mathrm{t}=3.17, \mathrm{p}<0.001)$ means that low-NFU people preferred the demand over supply appeal. Similarly, a negative regression coefficient for NFU $=9(b=-2.84, t=-2.79, p$ 
$<0.01)$ supports the finding that high-NFU participants preferred the supply over demand appeal. A similar pattern of results are obtained for the dependent variables purchase intention and perceived value. Thus, $\mathrm{H} 1$ is again fully supported.

\section{PLACE TABLE 3 ABOUT HERE}

Similar to study 1, we followed the procedures employed by Lamberton et al. (2013) to conduct a series of floodlight analyses to test the scarcity*NFU interaction at different levels of NFU ( X1, X2 etc.), albeit separately under the gain and loss frame. Once again we tested H2a by comparing the upper and lower panels of Table 4 for high-NFU people. Results from Table 4 (upper panel) show that the under the loss frame scarcity*NFU interaction is significant for attitude toward the brand (for values of NFU above 6), purchase intention (for NFU above 5) and for perceived value (for NFU above 8). Moreover, the negative coefficient for attitude toward the brand at NFU $=9(b=-2.84, t=-2.52, p<0.05)$ indicates that highNFU people prefer the supply over the demand appeal under the loss frame. We notice a similar pattern of results for purchase intention and perceived value for high-NFU people under the loss frame, thereby supporting H2a. Moreover, the lower panel of Table 4 also shows that high-NFU subjects prefer the demand over supply appeal under the gain frame, and this holds for attitude toward the brand, purchase intention and perceived value.

\section{PLACE TABLE 4 ABOUT HERE}

To test H2b, we again compared the lower and upper panel of Table 4, but for lowNFU people. Findings from the lower panel indicate that under the gain frame, scarcity*NFU interaction is significant for attitude toward the brand (for NFU levels 1 to 9), purchase intention (for NFU below 9) and for perceived value (for NFU above 2). Further, a positive regression coefficient for attitude toward the brand at $\mathrm{NFU}=1(\mathrm{~b}=1.75, \mathrm{t}=3.16, \mathrm{p}<0.01)$ means participants with low-NFU prefer the demand over supply appeal under the gain 
frame. This preference of demand over supply appeal is also noticed for purchase intention and perceived value as well. Results from the upper panel of Table 4 once again show that under the loss frame low-NFU people prefer the demand over the supply appeal, albeit for all the three outcome variables. Therefore similar to study 1, once again for low-NFU people, we find no difference in the preference for demand (vs. supply) appeal between loss (vs. gain) frames for low-NFU participants, as hypothesized in $\mathrm{H} 2 \mathrm{~b}$. Hence, H2b is not supported.

\section{Discussion}

Results of the second study not only replicate but also extend findings from the study 1. First, the pattern of results seems to hold when a different product category was used along with scenario-based manipulations. Second, results are replicated for the additional dependent variable 'perceived value', which the literature closely associates with scarcity appeal. As compared to our first study, results of floodlight analyses from the second study show that high-NFU people prefer the supply over demand appeal under the loss frame. This preference is sustained for all our dependent variables, including attitude, purchase intention and perceived value. Further, similar to study 1 we also found that under both the loss and gain frames low-NFU people prefer the demand over supply appeal. Our second study also shows that under the gain frame high-NFU people preferred the demand over supply appeal, which is supported by extant research showing that high-NFU people may yield to majority influence and seek conformity instead of distinctiveness, especially when they are cued with majority influences like providing information about demand for popular products (Van Herpen, Pieters, and Zeelenberg 2009; Simonson and Nowlis 2000).

\section{GENERAL DISCUSSION}

Across two studies, the key hypotheses are supported using different product categories (clothing versus smartphone), different manipulations (advertisement versus scenario) and a 
range of dependent variables related to advertising effectiveness and perceived value. Based on our findings, which show support for $\mathrm{H} 1$ and partial support for $\mathrm{H} 2$, the implications for both theory and practice are discussed below.

Our paper addresses several gaps in the literature. First, current research on the interaction between the type of scarcity appeal and NFU does not study its impact on consumer attitudes and behavioral intention. We fill this gap by showing that the scarcity*NFU interaction has an impact on attitudes and behavioral intentions. Secondly, evidence shows that consumers are influenced by their level of need for uniqueness as reflected in distinct cognitive and behavioral patterns (Simonson and Nowlis 2000). Our results further validate existing findings of Van Herpen, Pieters, and Zeelenberg (2009) and shows that the scarcity*NFU interaction is driven not only by different levels of NFU but also by different scarcity appeal types. Our results show that low (high) NFU consumers favored the demand (supply) over the supply (demand) scarcity appeal, leading to higher attitude towards the advertisement and brand, purchase intention and perceived value.

Most importantly, we explore the three way interaction (NFU*scarcity*framing) which to the best of our knowledge has not been examined so far. Findings show that high (low) NFU participants show differential preference for the scarcity appeal types under the loss versus gain frames. A gain (vs. loss) framing supports the risk-averse outlook for lowNFU people (Simonson and Nowlis 2000), and this combined with a demand (as compared to supply) appeal seems to be more persuasive for their decision making. In contrast, a loss (vs. gain frame) may provide support to the unique choices of high-NFU people and make them lean towards the supply (vs. demand) appeal. These findings may explain how judgments of uniqueness are shaped by message framing and scarcity appeal types, and responds to scholars call for more research in this area (Eisend 2008; Ames and Iyengar 2005). 
Our findings also have important managerial implications. First, our results suggest that advertiser can choose the most appropriate type of scarcity appeal in their ads based on consumers' motivation to seek conformity versus distinctiveness. For example, demandbased scarcity appeal should be used to signal bandwagon consumption, especially for people who seek conformity (e.g., low-NFU consumers). In contrast, supply-based scarcity appeals should be used more selectively to promote goods to people who seek distinctiveness (e.g., high-NFU consumers). Prior research supports similar motivation for high-NFU participants by showing that they are more likely to shop for products in non-conventional outlets or build their own collection of unique products (e.g., antiques) over time in order to distinguish themselves (Tian and McKenzie 2001).

Based on our findings about the impact of framing, advertisers should highlight the social benefits that may ensue from bandwagon consumption as gains, which would in turn motivate the low-NFU people. For high-NFU people, highlighting the losses combined with restricted availability (e.g., limited edition) may persuade them more successfully by supporting their pre-disposition for making unconventional choices. In view of prior findings that high-NFU people pay higher prices for unique products (Tian and McKenzie 2001); companies may engage such opportunities to charge a price premium under such situations.

In terms of communication, although scarcity appeal has often been used, the current study has some interesting findings regarding advertising effectiveness. Advertisers should highlight demand appeals with copies to induce consumers who seek conformity to think about the social gains associated (e.g., be part of a popular group). Such a strategy should enhance liking for the advert, the brand and ultimately lead to favorable purchase intention. However, if the product is really unique (e.g., an expensive customized handbag, an antique), advertiser should focus on highlighting the restricted availability and write copies that induce people with high uniqueness motivation to think about the losses incurred by not having the 
product. This should work well with high-NFU people by creating a positive attitude and purchase intention, and also by enhancing the value of the offering. We make these recommendations based on our findings.

However, findings from study 2 also show that high-NFU people can respond favorably to the demand appeal as compared to supply appeal under the gain frame. This supports extant findings for high-NFU people, who can also give in to majority influence especially when they are cued for such influence (Van Herpen, Pieters, and Zeelenberg 2009; Simonson and Nowlis 2000). From a managerial perspective this means that if the product is symbolic and demanded by majority, a gain frame may also appeal to high-NFU people. Advertising managers therefore gain from the fact that high-NFU people may also respond favorably to demand appeals under gain frame in addition to supply appeals under loss frame, as long as the cue for majority influence is made salient. For example, in our second study, we had a stronger manipulation of framing (gain vs. loss opportunity to look cool) and used a product (e.g., smartphone vs. apparel) which can denote symbolic consumption.

\section{LIMITATIONS AND FUTURE RESEARCH}

Our paper has a few limitations that future research may address. Firstly, we manipulated types of scarcity appeal through product advertisement (study 1) and scenarios (study 2). However, consumers can also infer scarcity from inventory levels in the store or from observing others, such as how many people visit a restaurant (Van Herpen, Pieters, and Zeelenberg 2009). Hence, future studies may inquire how such scarcity manipulation will be viewed by people with low and high levels of uniqueness motivation.

Secondly, we found that depending on the product category used in our study, highNFU people responded not only to supply appeal in study 1, but also additionally favored the demand appeal under the gain frame in study 2. This finding opens interesting avenues for 
future inquiries. For example, future study may manipulate the nature of product category (symbolic and personally relevant and hence more risky, versus ordinary and less risky) to see if a boundary condition for the effect observed for high-NFU people can be delineated. Additional studies replicating current findings for different product category (e.g., services) and across different cultures will also enhance generalizability.

Finally, past research (e.g., Simonson and Nowlis 2000) suggest that the underlying cognitive process for low (vs. high) NFU participants may be different, hence future studies can manipulate variables such as 'risk implications' and 'personal relevance' to explore the different styles of processing in response to message framing and scarcity appeal types. For the current work, we can however rule out this confound since our findings show that none of our independent variables had a direct effect on the key control variable "involvement" which is considered as an antecedent to these different information processing styles. 


\section{REFERENCES}

Aguirre-Rodriguez, Alexander (2013), "The Effect of Consumer Persuasion Knowledge on Scarcity Appeal Persuasiveness," Journal of Advertising, 42 (4), 371-379.

Aiken, Leona S. and Stephen G. West (1991), Multiple Regression: Testing and Interpreting Interactions. Thousand Oaks CA: Sage.

Ames, Daniel R., and Sheena S. Iyengar (2005), “Appraisal the Unusual: Framing Effects and Moderation of Uniqueness-Seeking and Social Projection," Journal of Experimental Social Psychology, 41 (3), 271-282.

Brehm, Jack W. (1966), A Theory of Psychological Reactance, New York: Academic Press.

Brock, Timothy C. (1968), "Implications of Commodity Theory for Value Change," in Psychological Foundations of Attitudes, Anthony G. Greenwald, Timothy C. Brock, and Thomas M. Ostrom, eds., New York: Academic Press, 243-275.

Eisend, Martin (2008), "Explaining the Impact of Scarcity Appeals in Advertising: The Mediating Role of Perceptions of Susceptibility," Journal of Advertising, 37 (3), 33-40.

Fromkin, Howard L., and Charles R. Snyder (1980), "The Search for Uniqueness and Valuation of Scarcity," in Social Exchange: Advances in Theory and Research, K. J. Gergen, M.S.

Gamliel, Eyal and Ram Herstein (2011), "To Save Or to Lose: Does Framing Price Promotion Affect Consumers' Purchase Intentions?" The Journal of Consumer Marketing, 28 (2),152-158.

Gierl, Heribert and Verena Huettl (2010), “Are Scarce Products Always More Attractive? The Interaction of Different Types of Scarcity Signals with Products' Suitability for Conspicuous Consumption, " International Journal of Research in Marketing, 27 (3), $225-235$

Imhoff, Roland and Hans-Peter Erb (2009), "What Motivates Nonconformity? Uniqueness Seeking Blocks Majority Influence," Personality and Social Psychology Bulletin, 35 (3), 309-320.

Irmak, Caglar, Beth Vallen and Sankar Sen (2010), "You Like What I Like, but I Don't Like What You Like: Uniqueness Motivations in Product Preferences," Journal of Consumer Research, 37 (3), 443-455.

Irwin, Julie R. and Gary H. McClelland (2001), "Misleading Heuristics and Moderated Multiple Regression Models," Journal of Marketing Research, 38 (February), 100-109.

Ku, Hsuan-Hsuan, Chien-Chih Kuo, and Tzu-Wei Kuo (2012), "The Effect of Scarcity on the Purchase Intentions of Prevention and Promotion Motivated Consumers," Psychology \& Marketing, 29(8), 541-548. 
Lamberton, Cait K. Kristofferson, and Darren W. Dahl (2013) "Taking the Joneses (and their Stuff) Down a Notch or Two: Consumer Envy, Harming Behaviours, and Outcome Valuation," (http://public-prod-acquia.gsb.stanford.edu/sites/default/files/documents/ mktg_11_13_Lamberton.pdf)

Levin, Irwin P., and Gary J. Gaeth (1988), "How Consumers are Affected by the Framing of Attribute Information Before and After Consuming the Product," Journal of Consumer Research, 15 (3), 374-378.

Lynn, Michael (1992), "The Psychology of Unavailability: Explaining Scarcity and Cost Effects on Value," Basic \& Applied Social Psychology, 13 (1), 3-7.

Lynn, Michael (1991), "Scarcity Effects on Value: A Quantitative Review of the Commodity Theory Literature," Psychology \& Marketing, 8 (1), 43-57.

Puto, Christopher P. (1987), “The Framing of Buying Decisions," Journal of Consumer Research, 14 (3), 301-315.

Rothman, Alexander J., and Peter Salovey (1997), "Shaping Perceptions to Motivate Healthy Behavior: The Role of Message Framing," Psychological Bulletin, 121 (1), 3-19.

Ruvio, Ayalla, Aviv Shoham and Maja Makovec Brencic (2008), "Consumers' Need for Uniqueness: Short-Form Scale Development and Cross-Cultural Validation," International Marketing Review, 25 (1), 33-53.

Simonson, Itamar and Stepehen M. Nowlis (2000), "The Role of Explanations and Need for Uniqueness in Consumer Decision Making: Unconventional Choices Based on Reasons," Journal of Consumer Research, 27 (1), 49-68.

Snyder, Charles R. (1992), "Product Scarcity by Need for Uniqueness Interaction: A Consumer Catch-22 Carousel?" Basic \& Applied Social Psychology, 13 (1), 9-24.

Snyder, Charles R., and Harold L. Fromkin (1980), Uniqueness: The Human Pursuit of Difference, New York: Plenum.

Spiller, Stephen A., Gavan J. Fitzsimons, John G. Lynch Jr, and Gary H. McClelland (2013), "Spotlights, floodlights, and the magic number zero: Simple effects tests in moderated regression," Journal of Marketing Research, 50 (2), 277- 288.

Tian, Kelly T., and Karyn McKenzie (2001), "The Long term Predictive Validity of the Consumers' Need for Uniqueness Scale,” Journal of Consumer Psychology, 10 (3), 171-193.

Tian, Kelly T., William, O. Bearden and Gary L. Hunter (2001), "Consumers Need for Uniqueness: Scale Development and Validation”, Journal of Consumer Research, 28 (1), 50-66.

Tversky, Amos and Daniel Kahneman (1981), "The Framing of Decisions and the Psychology of Choice," Science, New Series, 211 (4481), 453-458. 
Vakratsas, Demetrios and Tim Ambler (1999), "How Advertising Works: What Do We Really Know?" Journal of Marketing, 63 (1), 26- 43.

Van Herpen, Erika, Rik Pieters and Marcel Zeelenberg (2009), "When Demand Accelerates Demand: Trailing the Bandwagon," Journal of Consumer Psychology, 19 (3), 302 312.

Van Herpen, Erika, Rik Pieters and Marcel Zeelenberg (2005), "How Product Scarcity Impacts on Choice: Snob and Bandwagon Effects", in Advances in Consumer Research, Volume 32, Geeta Menon and Akshay R. Rao, eds., Duluth, MN: Association for Consumer Research, 623- 624. 
TABLE 1

Floodlight Analysis - Unstandardized Regression Coefficients (Study 1)

\begin{tabular}{|c|c|c|c|c|c|c|c|c|c|}
\hline \multirow[b]{2}{*}{ NFU } & \multicolumn{3}{|c|}{ Attitude towards the ad } & \multicolumn{3}{|c|}{ Attitude towards the brand } & \multicolumn{3}{|c|}{ Purchase Intention } \\
\hline & $\begin{array}{c}\text { H1: } \beta \\
\text { (Scarcity) } \\
\end{array}$ & t-value & $\mathbf{p}$ & $\begin{array}{c}\text { H1: } \beta \\
\text { (Scarcity) }\end{array}$ & t-value & $\mathbf{p}$ & $\begin{array}{c}\text { H1: } \beta \\
\text { (Scarcity) }\end{array}$ & t-value & $\mathbf{p}$ \\
\hline 1 & 3.64 & $\overline{5.22}$ & $<.001$ & 3.59 & 4.98 & $<.001$ & 3.57 & 4.48 & $<.001$ \\
\hline 2 & 2.96 & 5.19 & $<.001$ & 2.85 & 4.85 & $<.001$ & 2.83 & 4.35 & $<.001$ \\
\hline 3 & 2.27 & 5.04 & $<.001$ & 2.12 & 4.55 & $<.001$ & 2.10 & 4.07 & $<.001$ \\
\hline 4 & 1.58 & 4.54 & $<.001$ & 1.39 & 3.84 & $<.001$ & 1.36 & 3.41 & $<.001$ \\
\hline 5 & 0.90 & 3.15 & $<.001$ & 0.65 & 2.21 & $<.05$ & 0.62 & 1.92 & 0.06 \\
\hline 6 & 0.21 & 0.74 & 0.46 & -0.08 & -0.28 & 0.78 & -0.11 & -0.34 & 0.73 \\
\hline 7 & -0.48 & -1.36 & 0.17 & -0.82 & -2.27 & $<0.05$ & -0.85 & -2.13 & $<.05$ \\
\hline 8 & -1.16 & -2.58 & $<.01$ & -1.55 & -3.33 & $<.001$ & -1.58 & -3.08 & $<.01$ \\
\hline 9 & -1.85 & -3.29 & $<.001$ & -2.28 & -3.88 & $<.001$ & -2.32 & -3.57 & $<.001$ \\
\hline
\end{tabular}

Note: Values in the shaded areas represent the floodlight region for the respective dependent variables.

$$
* \mathrm{p}<.05, * * \mathrm{p}<.01, * * * \mathrm{p}<.001
$$


TABLE 2

Floodlight Analysis - Unstandardized Regression Coefficients (Study 1)

\begin{tabular}{|c|c|c|c|c|c|c|c|c|c|}
\hline $\begin{array}{l}\text { Loss } \\
\text { NFU }\end{array}$ & $\begin{array}{c}\text { Attitude t } \\
\text { H2: } \boldsymbol{\beta} \\
\text { Scarcity }{ }^{*} \mathrm{NFU} \\
\text { (loss frame) }\end{array}$ & $\begin{array}{l}\text { wards th } \\
\text { t-value }\end{array}$ & $\mathbf{p}$ & $\begin{array}{c}\text { Attitude t } \\
\text { H2: } \beta \\
\text { Scarcity*NFU } \\
\text { (loss frame) }\end{array}$ & wards th & $\begin{array}{r}\text { and } \\
\text { p }\end{array}$ & $\begin{array}{c}\text { Purch } \\
\text { H2: } \beta \\
\text { Scarcity*NFU } \\
\text { (loss frame) }\end{array}$ & se Intent & p \\
\hline 1 & 3.65 & 5.42 & $<.001$ & 3.59 & 4.93 & $<.001$ & 3.57 & 5.24 & $<.001$ \\
\hline 2 & 2.96 & 5.38 & $<.001$ & 2.85 & 4.81 & $<.001$ & 2.83 & 5.10 & $<.001$ \\
\hline 3 & 2.27 & 5.23 & $<.001$ & 2.12 & 4.52 & $<.001$ & 2.10 & 4.77 & $<.001$ \\
\hline 4 & 1.58 & 4.71 & $<.001$ & 1.39 & 3.81 & $<.001$ & 1.36 & 4.00 & $<.001$ \\
\hline 5 & 0.90 & 3.27 & $<.001$ & 0.65 & 2.19 & $<.01$ & 0.62 & 2.25 & $<0.05$ \\
\hline 6 & 0.21 & 0.77 & 0.44 & -0.08 & -0.28 & 0.78 & -0.11 & -0.40 & 0.69 \\
\hline 7 & -0.47 & -1.41 & 0.16 & -0.82 & -2.25 & $<.05$ & -0.85 & -2.49 & $<.05$ \\
\hline 8 & -1.16 & -2.68 & $<.01$ & -1.55 & -3.31 & $<.001$ & -1.58 & -3.61 & $<.001$ \\
\hline 9 & -1.85 & -3.37 & $<.001$ & -2.28 & -3.85 & $<.001$ & -2.32 & -4.18 & $<.001$ \\
\hline $\begin{array}{l}\text { Gain } \\
\text { NFU }\end{array}$ & $\begin{array}{c}\text { H2: } \beta \\
\text { Scarcity*NFU } \\
\text { (gain frame) }\end{array}$ & t-value & $\mathbf{p}$ & $\begin{array}{c}\text { H2: } \beta \\
\text { Scarcity*NFU } \\
\text { (gain frame) }\end{array}$ & t-value & $\mathbf{p}$ & $\begin{array}{c}\text { H2: } \beta \\
\text { Scarcity* NFU } \\
\text { (gain frame) }\end{array}$ & t-value & $\mathbf{p}$ \\
\hline 1 & 1.90 & 2.48 & $<.01$ & 1.65 & 2.18 & $<.05$ & 1.47 & 1.55 & 0.12 \\
\hline 2 & 1.64 & 2.62 & $<.01$ & 1.45 & 2.35 & $<.05$ & 1.32 & 1.70 & 0.09 \\
\hline 3 & 1.37 & 2.80 & $<.01$ & 1.25 & 2.57 & $<.05$ & 1.17 & 1.92 & 0.06 \\
\hline 4 & 1.11 & 2.97 & $<.01$ & 1.05 & 2.83 & $<.01$ & 1.02 & 2.19 & $<.05$ \\
\hline 5 & 0.85 & 2.86 & $<.01$ & 0.85 & 2.88 & $<.01$ & 0.87 & 2.36 & $<.05$ \\
\hline 6 & 0.59 & 2.02 & $<.05$ & 0.65 & 2.25 & $<.05$ & 0.72 & 2.00 & $<.05$ \\
\hline 7 & 0.32 & 0.90 & 0.37 & 0.45 & 1.26 & 0.21 & 0.57 & 1.28 & 0.20 \\
\hline 8 & 0.06 & 0.13 & 0.89 & 0.25 & 0.53 & 0.60 & 0.42 & 0.72 & 0.47 \\
\hline 9 & -0.20 & -0.33 & 0.74 & 0.045 & 0.08 & 0.94 & 0.27 & 0.36 & 0.72 \\
\hline
\end{tabular}

Note: Values in the shaded areas represent the floodlight region for the respective dependent variables.

$* \mathrm{p}<.05, * * \mathrm{p}<.01, * * * \mathrm{p}<.001$ 
TABLE 3

Floodlight Analysis Unstandardized Regression Coefficients (Study 2)

\begin{tabular}{l|ccc|ccc|ccc}
\hline & \multicolumn{3}{|c|}{$\begin{array}{c}\text { Attitude towards the brand } \\
\text { H1: } \boldsymbol{\beta}\end{array}$} & \multicolumn{3}{c|}{ Purchase Intention } & \multicolumn{3}{c}{ Perceived value } \\
NFU & $\begin{array}{c}\text { Scarcity) } \\
\text { t-value }\end{array}$ & $\mathbf{p}$ & $\begin{array}{c}\text { H1: } \boldsymbol{\beta} \\
\text { (Scarcity) }\end{array}$ & t-value & $\mathbf{p}$ & H1: $\boldsymbol{\beta}$ & t-value & $\mathbf{p}$ \\
\hline 1 & 1.88 & 3.17 & $<0.001$ & 2.10 & 2.63 & $<0.01$ & 2.36 & 3.27 & $<0.001$ \\
2 & 1.29 & 2.85 & $<0.01$ & 1.35 & 2.22 & $<0.05$ & 1.71 & 3.11 & $<0.01$ \\
3 & 0.70 & 1.98 & $<0.05$ & 0.61 & 1.27 & 0.21 & 1.06 & 2.48 & $<0.05$ \\
4 & 0.11 & 0.32 & 0.74 & -0.14 & -0.32 & 0.75 & 0.41 & 1.02 & 0.31 \\
5 & -0.48 & -1.19 & 0.24 & -0.89 & -1.64 & 0.10 & -0.23 & -0.48 & 0.63 \\
6 & -1.07 & -2.02 & $<0.05$ & -1.64 & -2.29 & $<0.05$ & -0.88 & -1.37 & 0.17 \\
7 & -1.66 & -2.43 & $<0.05$ & -2.39 & -2.59 & $<0.01$ & -1.53 & -1.84 & 0.07 \\
8 & -2.25 & -2.65 & $<0.01$ & -3.14 & -2.74 & $<0.01$ & -2.18 & -2.11 & $<0.05$ \\
9 & -2.84 & -2.79 & $<0.01$ & -3.89 & -2.83 & $<0.01$ & -2.83 & -2.28 & $<0.05$ \\
\hline
\end{tabular}

Note: Values in the shaded areas represent the floodlight region for the respective dependent variables.

$* \mathrm{p}<.05, * * \mathrm{p}<.01, * * * \mathrm{p}<.001$ 
TABLE 4

Floodlight Analysis - Unstandardized Regression Coefficients (Study 2)

\begin{tabular}{|c|c|c|c|c|c|c|c|c|c|}
\hline NFU & $\begin{array}{c}\text { Attitude tov } \\
\text { H2: } \beta \\
\text { Scarcity*NFU } \\
\text { (loss frame) }\end{array}$ & $\begin{array}{l}\text { ards the } \\
\text { t-value }\end{array}$ & and & $\begin{array}{c}\text { Purcl } \\
\text { H2: } \beta \\
\text { Scarcity }^{*} \text { NFU } \\
\text { (loss frame) }\end{array}$ & ase Inten & $\mathbf{p}$ & $\begin{array}{c}\text { H2: } \beta \\
\text { Perce } \\
\text { Scarcity* NFU } \\
\text { (loss frame) }\end{array}$ & ved Valı & $\mathbf{p}$ \\
\hline 1 & 1.88 & 2.87 & $<.01$ & 2.10 & 2.45 & $<.05$ & 2.36 & 3.00 & $<.01$ \\
\hline 2 & 1.29 & 2.58 & $<.05$ & 1.35 & 2.07 & $<.05$ & 1.71 & 2.85 & $<.01$ \\
\hline 3 & 0.70 & 1.79 & 0.08 & 0.60 & 1.19 & 0.24 & 1.06 & 2.27 & $<.05$ \\
\hline 4 & 0.11 & 0.29 & 0.77 & -0.14 & -0.30 & 0.76 & 0.41 & 0.94 & 0.35 \\
\hline 5 & -0.48 & -1.08 & 0.28 & -0.89 & -1.53 & 0.13 & -0.23 & -0.44 & 0.66 \\
\hline 6 & -1.07 & -1.82 & 0.07 & -1.64 & -2.14 & $<.05$ & -0.88 & -1.25 & 0.21 \\
\hline 7 & -1.66 & -2.20 & $<.05$ & -2.39 & -2.42 & $<.05$ & -1.53 & -1.69 & 0.10 \\
\hline 8 & -2.25 & -2.40 & $<.05$ & -3.14 & -2.56 & $<.01$ & -2.18 & -1.94 & 0.06 \\
\hline 9 & -2.84 & -2.52 & $<.05$ & -3.89 & -2.64 & $<.01$ & -2.83 & -2.10 & $<.05$ \\
\hline NFU & $\begin{array}{c}\text { H2: } \beta \\
\text { Scarcity*NFU } \\
\text { (gain frame) }\end{array}$ & t-value & $\mathbf{p}$ & $\begin{array}{c}\text { H2: } \beta \\
\text { Scarcity*NFU } \\
\text { (gain frame) }\end{array}$ & t-value & $\mathbf{p}$ & $\begin{array}{c}\text { H2: } \beta \\
\text { Scarcity* NFU } \\
\text { (gain frame) }\end{array}$ & t-value & $\mathbf{p}$ \\
\hline 1 & 1.75 & 3.16 & $<.01$ & 2.11 & 2.68 & $<.01$ & 0.48 & 0.70 & 0.48 \\
\hline 2 & 1.92 & 4.58 & $<.001$ & 2.16 & 3.62 & $<.001$ & 0.86 & 1.65 & 0.10 \\
\hline 3 & 2.09 & 6.51 & $<.001$ & 2.20 & 4.81 & $<.001$ & 1.23 & 3.08 & $<.01$ \\
\hline 4 & 2.27 & 7.56 & $<.001$ & 2.25 & 5.26 & $<.001$ & 1.61 & 4.30 & $<.001$ \\
\hline 5 & 2.44 & 6.64 & $<.001$ & 2.29 & 4.38 & $<.001$ & 1.99 & 4.33 & $<.001$ \\
\hline 6 & 2.62 & 5.35 & $<.001$ & 2.34 & 3.36 & $<.001$ & 2.36 & 3.87 & $<.001$ \\
\hline 7 & 2.79 & 4.41 & $<.001$ & 2.38 & 2.64 & $<.01$ & 2.74 & 3.46 & $<.001$ \\
\hline 8 & 2.97 & 3.76 & $<.001$ & 2.43 & 2.16 & $<.05$ & 3.11 & 3.16 & $<.01$ \\
\hline 9 & 3.14 & 3.31 & $<.01$ & 2.47 & 1.83 & 0.07 & 3.49 & 2.95 & $<.01$ \\
\hline
\end{tabular}

Note: Values in the shaded areas represent the floodlight region for the respective dependent variables.

$* \mathrm{p}<.05, * * \mathrm{p}<.01, * * * \mathrm{p}<.001$ 